\title{
Review: breast cancer is associated with a family history of the disease in first degree relatives
}

\author{
Collaborative Group on Hormonal Factors in Breast Cancer. Familial breast cancer: collaborative reanalysis of individual \\ data from 52 epidemiological studies including 58209 women with breast cancer and 101986 women without the \\ disease. Lancet 2001 Oct 27;358:1389-99.

\section{QUESTION: In women with a family history of breast cancer, how does the pattern of breast cancer in first degree relatives affect the risk for developing the disease?}

\author{
Sources of funding: \\ Imperial Cancer \\ Research Fund and \\ UNDP/UNFPA/ \\ WHO/World Bank \\ Special Programme of \\ Research, Development \\ and Research Training \\ in Human \\ Reproduction. \\ For correspondence: \\ ICRF Cancer \\ Epidemiology Unit, \\ Radcliffe Infirmary, \\ Oxford, UK. Fax +44 \\ (0)1865 310545 . \\ A modified version of \\ this abstract also \\ appears in \\ Evidence-Based \\ Nursing.
}

\section{Data sources}

Studies were identified by searching computerised literature databases, reviewing bibliographies of review articles, and contacting experts in the field.

\section{Study selection}

Selected studies were cohort or nested case control studies that included $\geqslant 100$ women with incident invasive breast cancer, and information about reproductive or hormonal factors was sought on each woman.

\section{Data extraction}

Principal investigators of the included studies were contacted for data on each woman regarding whether any of her first degree female relatives (mother, sisters, or daughters) had been diagnosed with breast cancer and, if so, their age when the diagnosis was made. Data were

\section{COMMENTARY}

The review by the Collaborative Group on Hormonal Factors in Breast Cancer (CGHFBC) reported an increased risk for breast cancer according to the number of affected first degree relatives (mother, sister, or daughter) and the age at which the relatives were diagnosed. This effect was pronounced in women below the age of 50 years and was highest when a relative was diagnosed below the age of 40 years (RR 13.5, 99\% CI 3.4 to 53.9). The review did not discuss women with hereditary breast cancer (eg, carriers of BRCA1 or BRCA2 mutations) as a separate group who indeed have higher risks for the disease. ${ }^{1}$

A family history of breast cancer is one of the few identified and most consistent determinants of breast cancer risk. Nevertheless, it is associated with relatively few cases in the population. In the CGHFBC study, approximately $13 \%$ of women with breast cancer had first degree relatives with the disease compared with $7 \%$ of women without the diagnosis. Clearly, a population-wide strategy of early detection aimed at women with a family history of the disease would miss most individuals with breast cancer because $87 \%$ would not have a positive family history.

How well do these risks apply to individuals? Rockhill et $a l^{2}$ found that the modified Gail model fits well in predicting numbers of breast cancer cases in specific categories of risk but did only slightly better than chance (concordance statistic $0.58,95 \%$ CI 0.56 to 0.60 ) on the individual level.

The CGHFBC study provides a useful ancillary guide in individual practices for identifying women at relatively high risk for breast cancer who can be counselled and monitored, while emphasising both the small numbers of women in these high risk categories and the reassuring fact that most women in these categories will not develop breast cancer.

Esther C Janowsky, MD, PhD University of North Carolina at Chapel Hill Chapel Hill, North Carolina, USA

1 Evans D, Lalloo F, Shenton A, et al. Uptake of screening and prevention in women at very high risk of breast cancer. Lancet 2001;358:889-90.

2 Rockhill B, Spiegelman D, Byrne C, et al. Validation of the Gail et al model of breast cancer risk prediction and implication for chemoprevention. J Natl Cancer Inst 2001;93:35866.

also collected on the numbers of sisters and daughters of each woman and the ages of each unaffected first degree female relative.

\section{Main results}

52 published and 2 unpublished studies included 58209 women with breast cancer (mean age 52 y) and 101986 women without breast cancer (mean age $53 \mathrm{y}$ ). 7496 women $(12.9 \%)$ with breast cancer and 7438 women $(7.3 \%)$ without had $\geqslant 1$ first degree female relative with a history of breast cancer. The risk for breast cancer increased with an increasing number of affected relatives (table 1). Age specific risk ratios (RRs) were not affected by race, age at menarche, education, height, weight, or use of contraceptives or hormone treatment. 27 studies provided data on the age that breast cancer was diagnosed in each first degree relative. The risk for breast cancer increased as the age of relatives who had been diagnosed with breast cancer decreased (table 2). The estimates of probability that a woman 20 years of age would develop breast cancer by age 50 were $1.7 \%$, $3.7 \%$, and $8.0 \%$ for women with 0,1 , and 2 affected first degree relatives, respectively. The corresponding lifetime probability estimates (ie, age 20 to $80 \mathrm{y}$ ) were $7.8 \%$, $13 \%$, and $21 \%$. The probability estimates for death were $2.3 \%, 4.2 \%$, and $7.6 \%$.

\section{Conclusions}

Women with first degree relatives with a history of breast cancer are at increased risk for developing the disease. The risk increases with an increasing number of affected relatives and is higher for younger than for older women.

Table 1 Relative risk (RR) for breast cancer by number of affected first degree female relatives

\begin{tabular}{lcl}
$\begin{array}{l}\text { Number of first } \\
\text { degree } \\
\text { relatives }\end{array}$ & $\begin{array}{l}\text { RR for women }<50 \\
\text { years }(99 \% \mathrm{Cl})\end{array}$ & $\begin{array}{l}\text { RR for women } \\
\geqslant 50 \text { years }(\mathrm{Cl})\end{array}$ \\
\hline 1 & $2.14(1.92$ to 2.38$)$ & $1.65(1.53$ to 1.78$)$ \\
\hline 2 & $3.84(2.37$ to 6.22$)$ & $2.61(2.03$ to 3.34$)$ \\
\hline 3 & $12.05(1.70$ to 85.16$)$ & $2.65(1.29$ to 5.46$)$ \\
\hline
\end{tabular}

Table 2 Relative risk (RR) for breast cancer by age of affected first degree female relatives

\begin{tabular}{lrl}
$\begin{array}{l}\text { Age at diagnosis } \\
\text { in first degree } \\
\text { relatives }\end{array}$ & $\begin{array}{l}\text { RR for women } \\
<50 \mathrm{y}(99 \% \mathrm{Cl})\end{array}$ & $\begin{array}{l}\text { RR for women } \\
\geqslant 50 \mathrm{y}(\mathrm{Cl})\end{array}$ \\
$<40 \mathrm{y}$ & $13.5(3.4$ to 53.9$)$ & $3.9(1.8$ to 8.6$)$ \\
\hline$\geqslant 40 \mathrm{y}$ & $7.8(2.4$ to 25.0$)$ & $2.6(1.8$ to 3.7$)$ \\
\hline
\end{tabular}

